\title{
Water-Based Aerosol for Book Deacidification: Experimental Apparatus and Theoretical Interpretation of Results
}

\author{
Giuseppe Chidichimo, Alessandra Crispini, Antonio Tursi *, Maria Rita Basile, Ilaria Lania, Giovanni De Filpo (D), \\ Cesare Oliviero Rossi (D) and Francesca Scarpelli
}

Department of Chemistry and Chemical Technologies, University of Calabria, 87036 Rende, Italy; giuseppe.chidichimo@unical.it (G.C.); alessandra.crispini@unical.it (A.C.); basimari88@gmail.com (M.R.B.); ilarialania.il@gmail.com (I.L.); giovanni.defilpo@unical.it (G.D.F.); cesare.oliviero@unical.it (C.O.R.); francesca.scarpelli@unical.it (F.S.)

* Correspondence: antonio.tursi@unical.it; Tel.: +39-098-449-3501

\section{check for}

updates

Citation: Chidichimo, G.; Crispini, A.; Tursi, A.; Basile, M.R.; Lania, I.; De Filpo, G.; Rossi, C.O.; Scarpelli, F. Water-Based Aerosol for Book Deacidification: Experimental Apparatus and Theoretical Interpretation of Results. Molecules 2021, 26, 4249. https://doi.org/ $10.3390 /$ molecules 26144249

Academic Editor: Maria Luisa Saladino

Received: 16 May 2021

Accepted: 9 July 2021

Published: 13 July 2021

Publisher's Note: MDPI stays neutral with regard to jurisdictional claims in published maps and institutional affiliations.

Copyright: (c) 2021 by the authors. Licensee MDPI, Basel, Switzerland. This article is an open access article distributed under the terms and conditions of the Creative Commons Attribution (CC BY) license (https:// creativecommons.org/licenses/by/ $4.0 /)$.

\begin{abstract}
One of the major problems in book conservation is the long-term deconstructive effect of acidity introduced into the paper by several additives, which, in the presence of humidity, generates a hydrogen cation with a strong catalytic role in cellulose depolymerization. Many types of treatment have been used in the past, but up to now, research for less-invasive, fast and cheap methods is still vividly ongoing. In this study, an approach to book deacidification is presented, where alkaline water solutions are administered to bound books in the form of micrometer-sized aerosol droplets, without using vacuum apparatus accessories. Alkaline clouds treatments were alternated with gentle air fluxes of drying steps. Few cycles are required to achieve uniform deacidification of books. The treatment could be conducted with proper apparatus on large volumes, resulting in rapid treatment time and low cost. The titration curve reporting the variation of book $\mathrm{pH}$, with respect to the amount of absorbed alkaline aerosol, was built and interpreted in terms of a chemical model for the neutralization process. FTIR, PXRD and XRF spectroscopies were used to characterize the book chemistry. The effects of the treatment on the book were evaluated by measuring the degree of polymerization (DP) of the paper and the colorimetric coordinates of the paper and ink. Artificial aging tests revealed a general increase in the aging stability of the deacidified paper samples with respect to the untreated samples. Finally, the alkaline reserve data are discussed.
\end{abstract}

Keywords: paper deacidification; pH; X-ray fluorescence; FTIR spectroscopy; PXRD; alkaline reserve

\section{Introduction}

The mass deacidification of paper works and library archives is currently a problem of considerable importance. Every year, tens of tons of books are treated in order to facilitate their conservation and usability and improve the appearance of the paper $[1,2]$.

Millions of tons of acid paper have been produced over the past two centuries, and acid paper is still mainly produced in Asia. It is estimated that $30 \%$ of Indian publications and about $5-10 \%$ of paper in Europe and the United States require deacidification processes. Several studies have evaluated the consequences of the hydrolysis and oxidation processes of hundreds of millions of bound and unbound paper documents in different collections around the world [2,3]. Cunha (1987) [4] estimated that a typical library loses about 5\% of the value of books each year, while Smith (1987) [5] calculated that the Library of Congress has losses of around USD 200,000 each day due to hydrolysis processes occurring during book storage.

The raw material usually used for the production of paper is cellulose, the most abundant organic polymer in nature, formed by glucose monomers organized in chains and linked together by hydrogen bonds [6,7]. Several past paper production techniques (especially those from the 19th century with the addition of alum rosin sizing and industrial paper production from wood) introduced conservation problems related to its acidity, including 
the acid-catalyzed depolymerization of cellulose and oxidative processes [8,9]. In particular, ancient paper artifacts have high acidity from their production due to the many substances added during the production process (alum, metal ions, rosin and additives) $[1,10]$. The presence of these substances and high levels of relative humidity dramatically promotes the acid hydrolysis of cellulose [11]. The bonds between the different glucose units $(1,4$ glycosidic bond of cellulose) are broken due to the insertion of water molecules, leading to the cleavage of the glycosidic bond (which results in a decrease in the degree of polymerization of cellulose), as illustrated in Figure 1 [1,12]. In addition to acid hydrolysis processes, oxidation reactions take place at the reducing end of polymer chains in the $\mathrm{C} 1$, $\mathrm{C} 2$ and $\mathrm{C} 3$ positions of the glycosidic ring generating acid species [13-15].

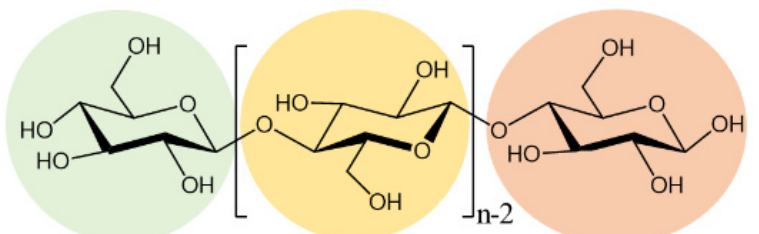

Non-reducing end Repeated unit Reducing end

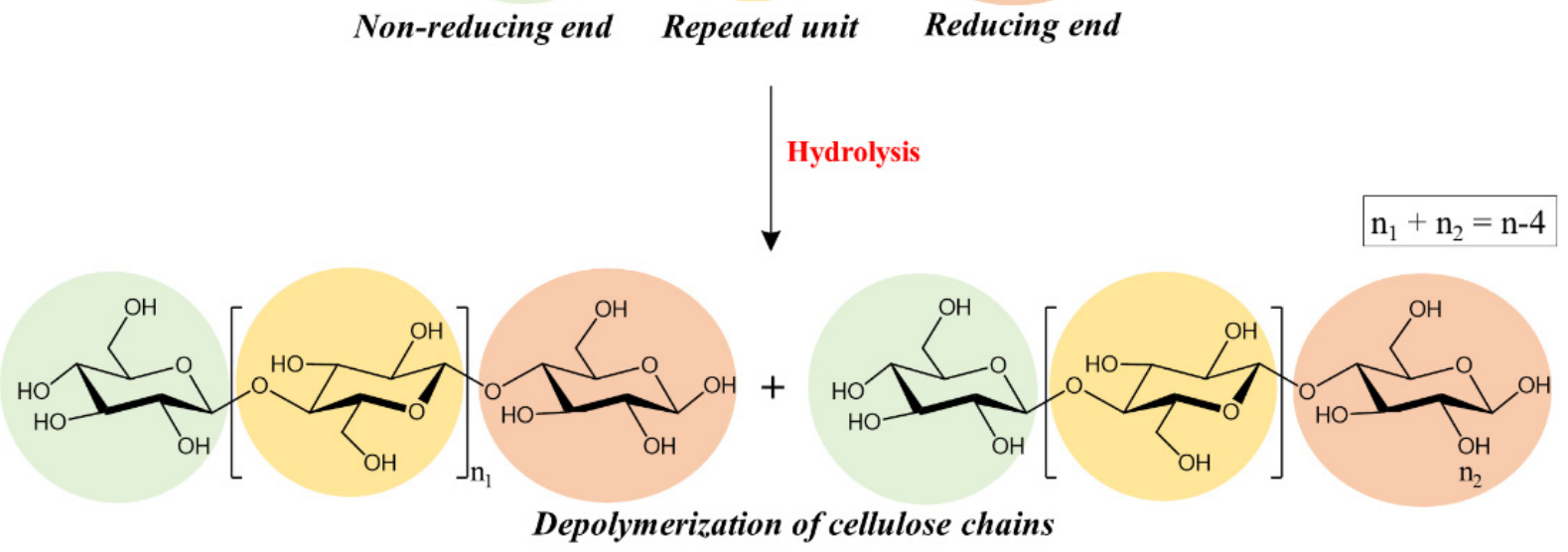

Figure 1. Hydrolysis of cellulose.

Concerning book preservation, an important common goal is to neutralize the acids already present in the paper and introduce an alkaline reserve to protect books from the possible formation of further acidic compounds during natural aging. In order to inhibit the acid-catalyzed cleavage reactions of the cellulose chains of the paper, the use of alkaline compounds allows neutralizing the protons $\left(\mathrm{H}^{+}\right)$responsible for the acidic $\mathrm{pH}$. Currently, several conservation and restoration methods are employed in order to deacidify the paper of books $[2,16]$. The most commonly used deacidification treatments, also carried out on entire volumes, are divided into two classes: non-aqueous and aqueous processes. The main non-aqueous processes involve the use of carrier fluids such as fluorinated liquids or hexamethyldisiloxane in combination with alkoxides of alkali metals (non-aqueous solution) or fluorinated liquid or heptane as carrier fluids with $\mathrm{MgO}$ or other alkaline particles (non-aqueous dispersion) $[2,17,18]$. Some of the most accredited methods for deacidification, still in use and not, which can also be used for the treatment of entire volumes, are presented below:

1. The "Vienna process", conceived in the 1970s, involves immersing the entire volume in vacuum in a solution of calcium hydroxide and methylcellulose as a consolidant [19]. The system is still used for the deacidification of newspapers [20];

2. The "Sablè" method is a French variation of the Wei T'o system invented by Richard D. Smith and developed by the National Archive in Canada. It was adopted between 1987 and 1989. The system consists of the insertion of open volumes, kept in a vertical position inside metal baskets, into an autoclave. The volumes are first dried at $45{ }^{\circ} \mathrm{C}$ and then impregnated for $10 \mathrm{~min}$ with a mixture consisting of ethoxy-magnesium carbonate and ethanol [21,22]; 
3. The Bookkeeper ${ }^{\circledR}$ method, devised in 1985 , is based on the use of magnesium oxide microparticles dispersed in perfluoroheptane and the addition of a surfactant. The volumes are placed on vertical supports and opened at an angle of $90^{\circ}$ and then placed inside four reactors that operate sequentially and can treat 32 volumes in $2 \mathrm{~h}$. The deacidifying product is inserted, after establishing vacuum conditions. This is one of the most popular methods for its speed of execution and relatively low costs. The Bookkeeper ${ }^{\circledR}$ method provides a considerable reduction of paper degradation and does not affect inks and book ligatures. However, it is reported in the literature that this method appears less efficient for the treatment of large-sized books due to the fact that the alkaline reserve is low and the deacidification is not very uniform. The solvent seems to have a low penetration capacity into the paper fibers, and some white patina appears on the surface $[2,21,23,24]$;

4. The "CSC Booksaver" method, developed in 2001, involves the use of n-propylated magnesium carbonate dispersed in heptafluoropentane. The volumes are first dehydrated and then impregnated with the deacidifying substance [20,25];

5. The "ZFB:2" method, devised in 2011 , uses calcium carbonate and magnesium oxide dispersed in heptane. The volumes are not opened, and the process takes about four weeks [26];

6. The "Papersave" method from Battelle Ingenieurtechnik GmbH and the "Papersave Swiss" method use magnesium and titanium ethyloxides dissolved in hexa-dimethyl siloxane and provide good penetration and an alkaline reserve, reducing the degradation of cellulose with aging. However, the treatment cannot be applied to leather covers, pergamene covers, patinated papers and newspapers. Inconvenient decreases in paper mechanical strength, discoloration, white deposits and ink bleeding have been observed [27].

In general, it is asserted that the non-aqueous methodologies mentioned above have disadvantages and limitations such as the accumulation of by-products on the surface of the paper during the treatment process, the use of compounds that alter the appearance of the treated documents (non-aqueous treatments with magnesium compounds) and the use of solvents that are not environmentally friendly and/or that could also solubilize the inks, as well as the absence of the washing action of the water, which prevents the solubilized products from moving away [28-30]. Ultimately, all these methodologies require improvements to further facilitate the penetration of the deacidifying solution between the pages, increase the alkaline reserve and avoid the mentioned problems. In non-aqueous solvents, the alkaline medium remains at the state of micrometer-sized particles, and for this reason, they cannot easily penetrate into the paper fibers. In fact, there is evidence that they mostly remain on the external surfaces of paper sheets, rather than in the interior of the sheets [31], and that treatment applied to one side of paper by spray application does not affect the opposite sides [32]. On the other hand, the processes based on the use of aqueous solutions ensure good penetration of the solvent in the paper due to the hydrophilic character of cellulose. These should give, in principle, better spatial homogeneity and bigger alkaline reserves. Further, certain biocide protection should be given by the aqueous solution containing appropriate compounds, which, indeed, are very soluble in water [33].

One of the most used aqueous methodologies [34] consists of their complete disassembly and the immersion of single pages in two solutions: one of $\mathrm{Ca}(\mathrm{OH})_{2}$, which counteracts the acidity present, and one of $\mathrm{Ca}\left(\mathrm{HCO}_{3}\right)$, which deposits an alkaline reserve. The sheets are then left to dry, and the book is stitched back. However, this process is very expensive both in terms of time and money and allows treating only one book at a time $[6,30,35]$.

Since the beginning of the 21st century, up to now, several patents [36-41] have appeared on book deacidification by means of a basic water solution fed to book pages in the form of aerosol droplets. These patented methods [36-41] make use of vacuum techniques at least in one of the process steps such as droplet injection or the subsequent drying of books. This condition introduces a certain degree of complexity to the treatment 
apparatus and represents a sort of limitation factor with respect to the diffusion of this interesting methodology.

\section{Materials and Methods}

\subsection{Aerosol System}

The book deacidification experiments were performed by means of the homemade experimental apparatus shown in Figure 2.

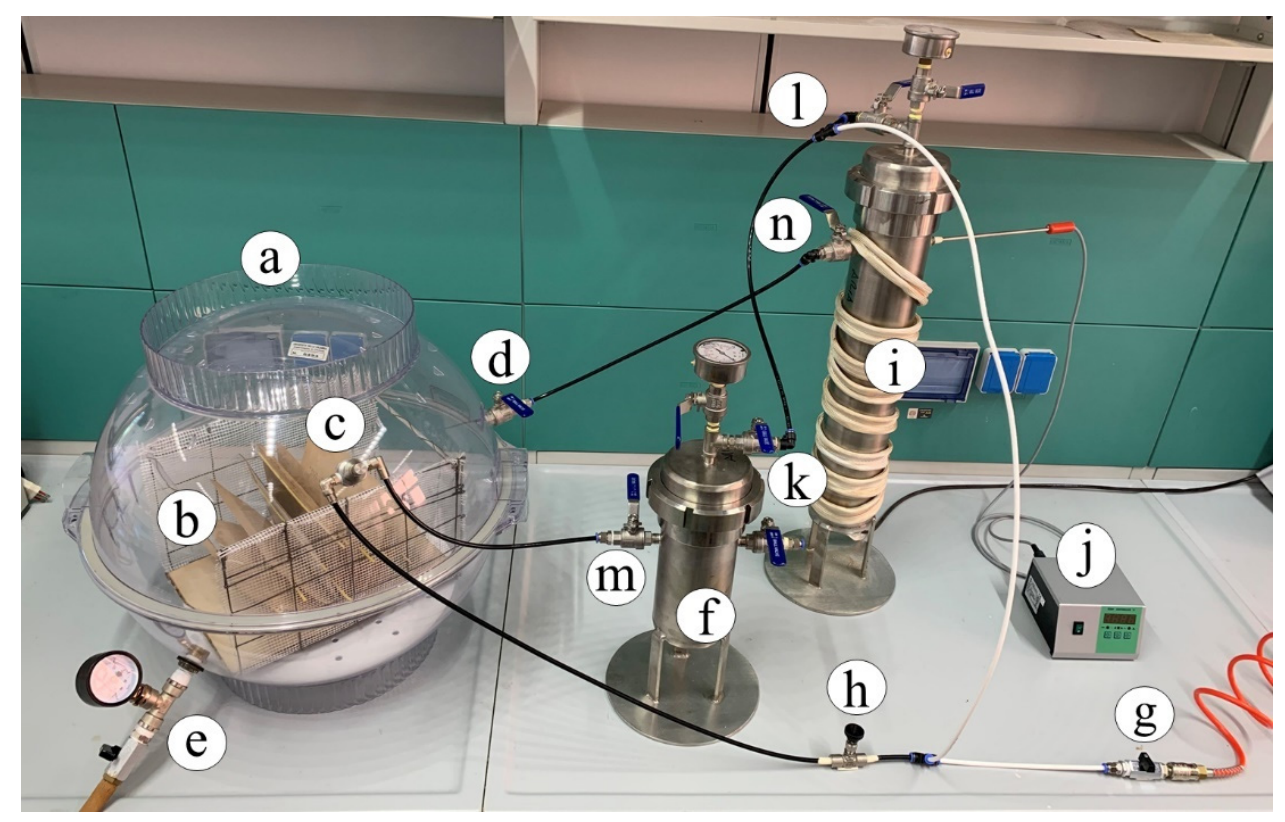

Figure 2. Deacidification homemade apparatus: (a) chamber hosting the book during treatment cycles; (b) book; (c) nuzzle nebulizer; (d) valve for dry air inlet; (e) valve for the exit of the drying air; (f) steel vessel alkaline solution container; (g) inlet compressed air; (h) T-valve connector; (i) steel desiccator; (j) temperature control device; $(\mathbf{k}-\mathbf{n})$ flux control valves.

The chamber (Figure 2a) hosting the book (Figure 2b) during the deacidification treatment was a polypropylene flask made by two airtight hemispheric sectors overlapping along the equatorial circumference with a volume of $65 \mathrm{~L}$. The book was suspended below the equatorial plane of the flask by means of an appropriate grid. An IKEUCHI BIMK6004 S303 nozzle nebulizer (TKK Corporation, Thailand) (Figure 2c), able to uniformly spread a basic solution cloud in the form of 20-30 $\mu \mathrm{m}$ droplets on the open book pages, was mounted on the superior hemisphere of the flask. On the same superior hemisphere of the flask, a connector carrying a valve for dry air inlet (Figure 2d) was placed. The bottom hemisphere was fitted with an additional valve (Figure 2e) to allow the exit of the drying air to the external environment and maintain the inner of the flax at room pressure. A $\mathrm{Ca}(\mathrm{OH})_{2}$ saturated water solution with a $\mathrm{pH}$ equal to 12.24 (molar concentration of $\mathrm{Ca}(\mathrm{OH})_{2}$ equal to $8.7 \times 10^{-3} \mathrm{~mol} \cdot \mathrm{L}^{-1}$ ) was provided for deacidification means by using the steel vessel (Figure 2f). The basic solution was fed into the flask from the bottom of this container by pressurizing the surface of the solution at a pressure of $1.5 \mathrm{~atm}$ by means of an air compressor (not shown in the figure) connected through a valve (Figure $2 \mathrm{~g}$ ). The compressor, by means of the T-connector (Figure $2 \mathrm{~h}$ ), further fed the air required by the nozzle. Once a humidification stage of the book pages was completed, warm and dry air, coming from the steel desiccator (Figure 2i), filled with silica gel, and thermostated by the power supply and controller (Figure 2j), was passed through the flask (Figure 2a). During the drying stages, the bottom valve of the flask (Figure 2e) was kept open, and all valves (Figure $2 \mathrm{~h}, \mathrm{k}-\mathrm{n}$ ) were manually settled to cut the fluxes in and from the steel vessel (Figure 2f) and maintain the fluxes in and from desiccator (Figure 2i). In order to ensure a uniform spread of the nebulized solution, pages were maintained well and separated from 
each other by using a grid holder, where appropriate tin wood rods could be inserted as page spacers, as indicated in Figure 3.

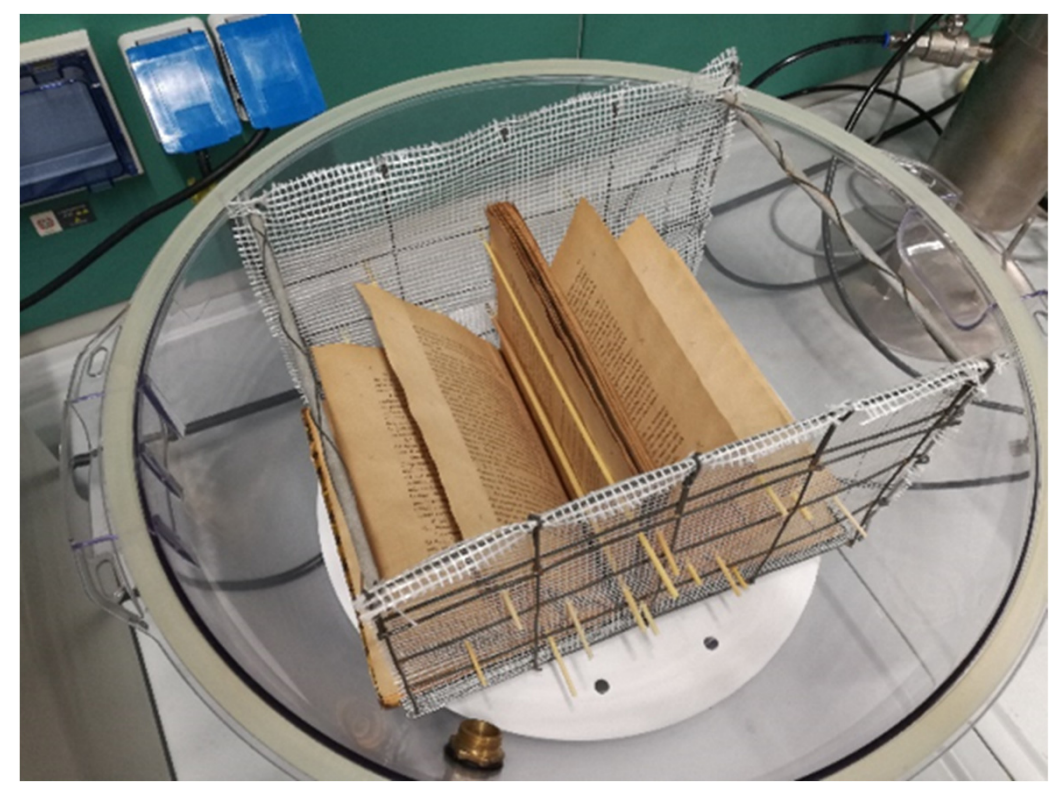

Figure 3. Details of the book holder grid with page spacers.

Deacidification experiments were performed according to the following steps:

1. The book "Studi di Enologia" del cav. Angelo Mona (Brescia-Pio Istituto Pavoni1875), the title page of which is shown in Figure 4, after being weighed, was supported on the holder, as indicated in Figure 2b, and inserted into the flask. At the actual development stage of our homemade apparatus, only a limited number of pages could be homogeneously treated with the alkaline droplets. For this reason, only 12 (from 1 to 6 and from 91 to 96 pages) of the almost 200 pages of the book were kept wide open to facilitate a uniform deposition of the aerosol through a single nozzle. The other pages were kept firmly closed in order to exclude them from the deacidification process;

2. The book, placed into the flask, was exposed to a dry air flux at the temperature of $45^{\circ} \mathrm{C}$ for $15 \mathrm{~min}$. Then, it was extracted from the chamber and weighed. The weight variation was $3.45 \%$;

3. The book was replaced in the chamber. A cloud of nebulized solution was fluxed above the open pages through the nozzle placed on the top hemisphere. The aerosol inlet was left to flow for $3 \mathrm{~min}$, while the valve on the bottom of the flask was kept open to ensure a constant pressure in the flask;

4. The book was removed from the flask and weighed in order to measure the amount of the absorbed basic solution and inserted back into the treatment chamber;

5. Dry air at the temperature of $45^{\circ} \mathrm{C}$ was let gently fluxed into the flask for $3 \mathrm{~min}$, entering with the help of a small pressure gradient (around $0.05 \mathrm{~atm}$ ) and exiting through the bottom open valve. The rehydration of the air gradually removed the absorbed humidity from the book. After the above dehydration cycle, the book was weighed. This step was repeated 5 times in order to bring the book to a constant weight;

6. The $\mathrm{pH}$ on every treated page was measured in six different points, as described in Section 2.4, and the average value was recorded;

7. The procedure described above, as defined in Steps 3 to 6, was repeated 8 times in order to reach a satisfactory $\mathrm{pH}$ value. 


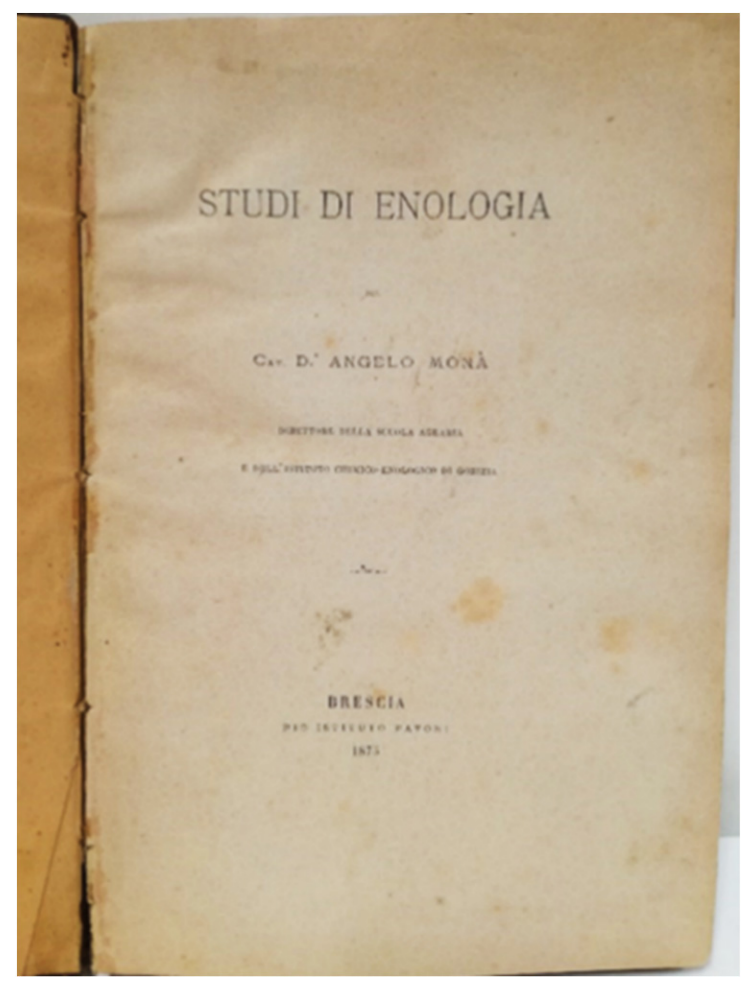

Figure 4. Photography of the title page of the analyzed book.

\subsection{X-ray Fluorescence (XRF)}

Analysis was performed by a Bruker Tracer III with an $\mathrm{Rh} / \mathrm{Pd} \mathrm{X}$-ray source under the following conditions: voltage, $40 \mathrm{kV}$; current, $11 \mu \mathrm{A}$; acquisition time, $15 \mathrm{~s}$. Measurements were taken in six different points of the pages in all 12 pages investigated. XRF data were evaluated by Artax software from Bruker. The software provides qualitative and partially semi-quantitative information with respect to the elements detected. These data represent the values of the integrals subtended by the characteristic peaks of the emitted fluorescence by the different detectable elements. They depend in principle on many factors, but when measurements are appropriately made, it can be assumed that XRF intensities are in the first approximation proportional to the density of the chemical elements dispersed into the sampled volume and to a specific emission constant, which is different for each of the elements. Thus, significant information on the chemistry of the book could be derived from XRF signals.

\subsection{FTIR Spectroscopy}

FTIR-ATR analysis was performed by using the FTIR ATR BRUKER ALPHA II spectrophotometer equipped with the accessory for attenuated total reflectance (ATR) with a diamond and crystal window. Analysis was carried out with a resolution of $4 \mathrm{~cm}^{-1}$ in the region between 4000 and $375 \mathrm{~cm}^{-1}$, setting 48 scans for a single analysis. The recorded spectra were interpreted using the Bruker OPUS software.

\subsection{Powder X-ray Diffraction (PXRD)}

PXRD patterns were acquired on a Bruker D2-Phaser equipped with $\mathrm{Cu} \mathrm{K} \alpha$ radiation $(\lambda=1.5418 \mathrm{~A})$ and a Lynxeye detector, at $30 \mathrm{kV}$ and $10 \mathrm{~mA}$, with a step size of $0.01^{\circ}$ and a step time of $1.5 \mathrm{~s}$ (acquisition time: $11,250 \mathrm{~s}$ ), over an angular range of 5-80 $2 \theta$. A $1 \mathrm{~cm}^{2}$ area of the book was sacrificed to perform the PXRD analysis before and after deacidification treatment. Small pieces of paper sheets, as they were, were placed on a zero-background sample holder. Slight $2 \theta$ displacements of some reflection peaks, which did not exceed $\pm 0.3^{\circ}$, with respect to the reference patterns reported in the Crystallography 
Open Database (COD) and in the RRUFF database, could be ascribed to both the sample preparation and the instrumental set-up.

\subsection{Contact $p H$ Meter}

The surface pH method (TAPPI T 529 om99) [42] was used for the pH measurement. Measurements of $\mathrm{pH}$ in standard conditions were made by placing a polypropylene plastic sheet beneath the investigated page. On each of the measurement points, a $40 \mu \mathrm{g}$ drop of MilliQ water (HANNA HI70960 conductive electrolyte solution) was added dropwise by a droplet-dosing cup bottle. The surface electrode was then set on the water droplet. Both these operations were performed in rapid succession in a time lower than $1 \mathrm{~s}$. The pH was measured by a HANNA_-Leather and Paper HI $99171 \mathrm{pH}$ meter with a surface glass. Reported $\mathrm{pH}$ values are the mean values calculated from the $\mathrm{pH}$ measurements, taken from six test points, in each of the twelve pages investigated.

\subsection{Artificial Aging}

Artificial aging tests were performed according to the methods developed by the Conservation Processes and Materials Research Division of the Canadian Conservation Institute (CCI) in Ottawa (Canada) and the Preservation Research a Testing Office of the U.S. Library of Congress (LOC) in Washington (USA) [43]. Six strips of about $0.2 \mathrm{~g}$, taken from all of the deacidified book pages (from 1 to 6 and from 91 to 96), and six analogous strips, cut from 41 to 46 and from 107 to 112 pages (taken out from the book before any treatment), were aged. All paper samples were conditioned at $23{ }^{\circ} \mathrm{C}$ and $50 \%$ $\mathrm{RH}$ for $\geq 24 \mathrm{~h}$ both immediately prior to and following the accelerated aging period. The preconditioned paper samples were inserted inside closed glass bottles with a proportion of paper weight/bottle volume of $1 \mathrm{~g} / 36 \mathrm{~mL}$ and introduced into the heated oven at $100{ }^{\circ} \mathrm{C}$ for $120 \mathrm{~h}$ in one continuous period.

\subsection{Colorimetry and Optical Microscopy}

Colorimetric measurements CIE $\mathrm{L}^{*} \mathrm{a}^{*} \mathrm{~b}^{*}$ were performed to ascertain the effect of the deacidification treatments on paper and ink color before and after aging. The ARW-265 portable colorimeter (Arroweld Italia Spa, Italy) with a measurement caliber of $8 \mathrm{~mm}$ was used in the D65/10 (light source) mode. The paper colorimetric coordinates were measured, for all sample types (untreated: Pages 41, 44, 45, 107, 109, 112; deacidified: Pages 1, 4, 5, 92, 93 and 95; untreated and aged: corresponding aged strips of Pages 41, 44, 45, 107, 109 and 112; deacidified and aged: corresponding aged strips of Pages 1, 4, 5, 92, 93 and 95), on six different testing points, opportunely chosen on each of the abovementioned book pages. In particular, the colorimetric ink investigations were performed, according to Sequeira et al. (2006) [1], on six "a" letters for each of the different page samples. The total color difference $\left(\Delta \mathrm{E}^{*}\right)$ and the whiteness parameter $(\mathrm{W})$ were calculated according to Brainard (2003) [44] and Gooch (2011) [45], respectively. The averaged values and standard deviations were determined. The script character was observed by a Zeiss Telaval 31 inverted phase contrast optical microscope (Zeiss, Oberkochen, Germany) with an S5A-6V halogen lamp $(25 \mathrm{~W})$ as a light source in order to detect the presence of eventual bleeding effects.

\subsection{Determination of the Degree of Polymerization (DP)}

The polymerization degree for each of the different paper sample types, as in the case of the colorimetric measurement (untreated, deacidified, untreated and aged, deacidified and aged), was determined according to the UNI 8282 standard test [46] by measuring the viscosity limit of cellulose solutions in bis-(ethylenediamine)-copper (II) hydroxide (CED) $0.5 \mathrm{M}$. The CED solution was prepared by diluting the Aldrich ${ }^{\circledR} 1 \mathrm{M}$ CED solution in water. A $10 \mathrm{mg}$ amount of paper for each paper sample was dissolved in $20 \mathrm{~mL}$ of $\mathrm{CED}$ at $25^{\circ} \mathrm{C}$ by stirring the system for at least $30 \mathrm{~min}$. In order to obtain the required limit viscosities, 5 solutions for each of the investigated paper samples were analyzed: 
the base solutions, obtained as described above, and 4 solutions, obtained by diluting the base solution with 0.5 M CED. Four dilution ratios, 2, 4, 8 and 16, were used. Viscosity measurements were carried out at room temperature $\left(25^{\circ} \mathrm{C}\right)$ using an RFS III shear-straincontrolled rheometer (Rheometrics Co. Ltd., Piscataway, NJ, USA) equipped with parallel plate geometry (gap, $1.000 \pm 0.001 \mathrm{~mm}$; diameter, $50 \mathrm{~mm}$ ) for the samples analyzed and a Peltier system $\left( \pm 0.1^{\circ} \mathrm{C}\right)$ for temperature control. Steady flow experiments were performed, and the viscosity was measured at different shear rate values. The variation of viscosity versus shear rates for all samples was measured. It was observed that all samples had Newtonian rheological behaviors, which meant the viscosity was independent of the shear rates. Specific $[\eta]$ viscosity was obtained according to Equation (1):

$$
[\eta]=\lim _{c \rightarrow 0} \frac{\eta_{\mathrm{sp}}}{c}
$$

where $c$ is the solution concentration, and $\eta s p=(\eta-\eta s) / \eta s$, where $\eta s$ is the viscosity of the CED solvent by determining the vertical intercept of the $\eta$ sp plot versus the concentration. Finally, the degree of polymerization (DP) was calculated according to the equation: DP $=1.33[\eta]^{0.905}$, according to UNI 8282:1994 [46]. Mean values, obtained by averaging those measured from Pieces 41/42, 43/44, 45/46, 107/108, 109/110 and 111/112 of untreated and untreated-aged book pages and those measured from Pieces 1/2, 3/4, 5/6, 91/92, 93/94 and 95/96 of deacidified and deacidified-aged book pages, were reported.

\subsection{Alkaline Reserve Determination}

The alkaline reserve was determined according to the TAPPI 533 pm-92 method [47]. A $1 \mathrm{~g}$ amount of dry small paper pieces, taken in equal amounts from the untreated book pages and analogous quantities of paper taken from the deacidified pages, were used to investigate the original (before treatment) and final (after treatment) alkaline reserve, respectively. Each gram of the two of these paper samples was inserted into $25 \mathrm{~mL}$ of distilled water. A $20 \mathrm{~mL}$ volume of $\mathrm{HCl} 0.1 \mathrm{~N}$ solution was added to the suspension, which was then left for about $1 \mathrm{~min}$ at boiling temperature. After cooling, the suspension was titrated with a $\mathrm{NaOH} 0.1 \mathrm{~N}$ solution monitoring the color change of the indicator (close to $\mathrm{pH}=7$ ) previously added.

\section{Results and Discussion}

Before discussing the deacidification process and the related model, FTIR, PXRD and XRF data will be presented in order to obtain a useful indication of the book chemistry. Spectral data were taken from the pages of the book kept open during the acidification process before and at the end of the deacidification treatment. pH values were measured, on the same pages, before the treatment and after each of the eight used aerosol/drying cycles. After discussing the deacidification process data, the effect of treatment on the degree of polymerization (DP) of the paper and the colorimetric coordinates of paper and ink, the variation of these parameters with aging and, finally, the alkaline reserve data will be discussed.

\subsection{FTIR Results}

FTIR spectra are substantially equal for all the 12 pages investigated. Two copies of these spectra, precisely those recorded from Page 1, in pre- and post-treatment conditions, are reported in Figure 5, together with the transition wavenumbers.

Those related to cellulose are reported in blue [48-50]. The identification of vibrational bands is reported in Table 1. 


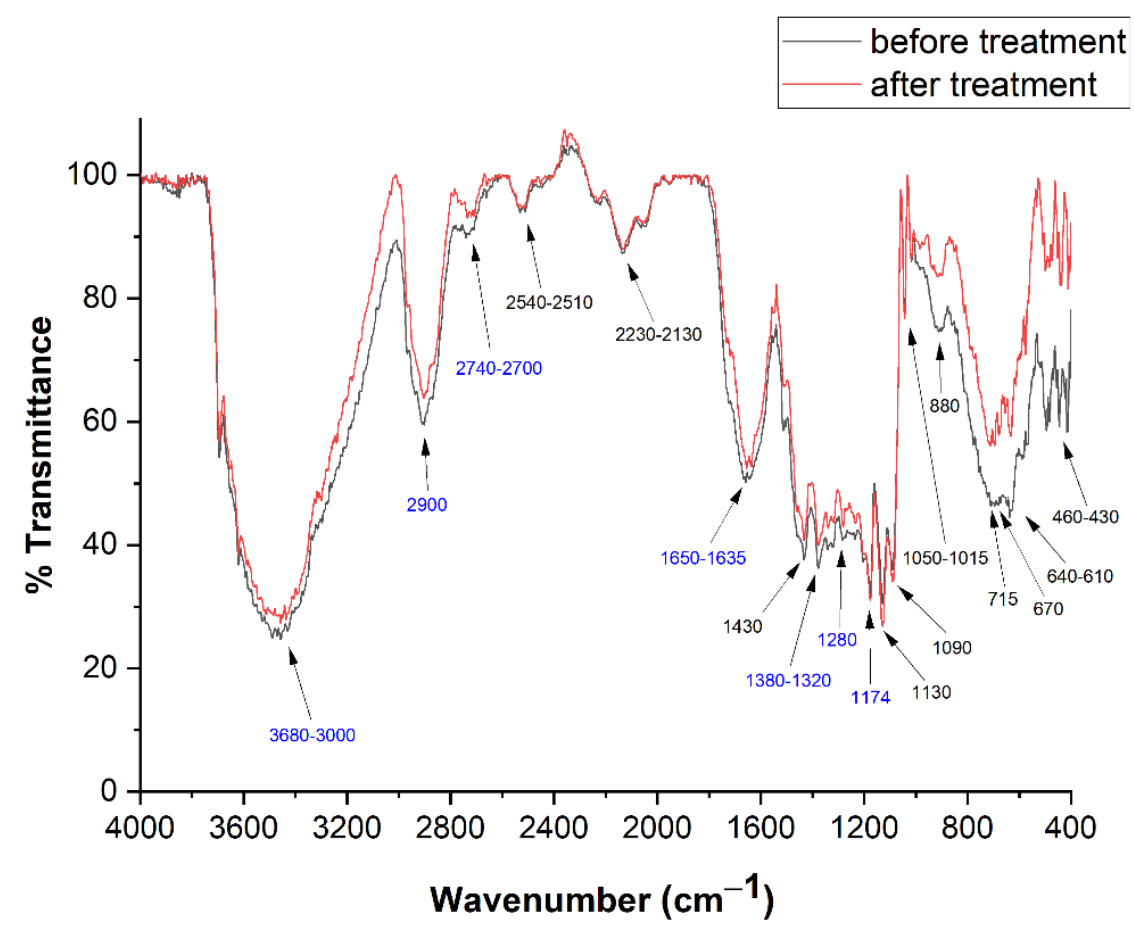

Figure 5. FTIR spectra before (black) and after (red) deacidification treatment recorded from page 1. Frequency values in blue are identified as cellulose peaks.

Table 1. FTIR wavenumbers, vibrational mode and related chemical compounds (cellulose bands are in blue) (Miller and Wilkins 1952; Garside and Wyeth 2003; Sequeira et al., 2006; Librando et al., 2011).

\begin{tabular}{|c|c|c|}
\hline Wavenumber $\left(\mathrm{cm}^{-1}\right)$ & Functional Chemical Groups & Chemical Compound \\
\hline $3680-3000$ & $\mathrm{OH}$ stretching & Cellulose \\
\hline 2900 & $\mathrm{CH}$ stretching & Cellulose \\
\hline $2740-2700$ & $\mathrm{CH}$ stretching & Cellulose \\
\hline $2540-2510$ & CO stretching & $\mathrm{CaCO}_{3}$ \\
\hline $2230-2130$ & CO stretching & $\mathrm{CaCO}_{3}$ \\
\hline 1735 & $\mathrm{C}=\mathrm{O}$ stretching & Cellulose \\
\hline $1650-1635$ & $\mathrm{OH}$ bending/adsorbed water & Cellulose and others \\
\hline 1430 & CO stretching & $\mathrm{CaCO}_{3}$ \\
\hline 1372 & $\mathrm{CH}$ bending & Cellulose \\
\hline 1340 & $\mathrm{CH}$ bending & Cellulose \\
\hline 1320 & $\mathrm{CH}$ bending & Cellulose \\
\hline 1280 & $\mathrm{CH}_{2}$ twisting & Cellulose \\
\hline 1174 & C-C stretching & Cellulose (and others) \\
\hline 1130 & SO stretching asym & $\mathrm{Ca}\left(\mathrm{SO}_{4}\right) \cdot 2 \mathrm{H}_{2} \mathrm{O}$ \\
\hline 1090 & CO stretching asym & $\mathrm{CaCO}_{3}$ \\
\hline $1050-1015$ & SO stretching & $\mathrm{Ca}\left(\mathrm{SO}_{4}\right) \cdot 2 \mathrm{H}_{2} \mathrm{O}$ \\
\hline $870-880$ & $\mathrm{CO}$ stretching asym & $\mathrm{CaCO}_{3}$ \\
\hline 715 & CO stretching asym & $\mathrm{CaCO}_{3}$ \\
\hline 670 & $\mathrm{Ca}-\mathrm{OH}$ bending & $\mathrm{Ca}\left(\mathrm{SO}_{4}\right) \cdot 2 \mathrm{H}_{2} \mathrm{O}$ \\
\hline $640-610$ & $\mathrm{Ca}-\mathrm{OH}$ bending & $\mathrm{CaCO}_{3}$ \\
\hline $460-430$ & $\mathrm{Ca}-\mathrm{OH}$ stretching & $\mathrm{CaCO}_{3}$ \\
\hline
\end{tabular}

An intense band, between 3680 and $3000 \mathrm{~cm}^{-1}$, is related to the $\mathrm{OH}$ stretchings of cellulose [46] and absorbed water, while the bending of this species appears at $1635 \mathrm{~cm}^{-1}$ [48]. The intensity of these bands is, of course, related with the degree of the paper hydration.

Cellulose $\mathrm{CH}$ stretchings appear between 2900 and $2740-2700 \mathrm{~cm}^{-1}$ [48], while $\mathrm{CH}$ bendings are at 1372,1340 and $1320 \mathrm{~cm}^{-1}$ [49]; $\mathrm{CH}_{2}$ twistings and $\mathrm{C}=\mathrm{O}$ stretchings are, respectively, at 1280 and $1735 \mathrm{~cm}^{-1}[48,49]$. The band between 610 and $640 \mathrm{~cm}^{-1} \mathrm{can}$ 
be attributed to $\mathrm{Ca}-\mathrm{OH}$ bending [1]. On the other hand, spectra show the presence of calcium sulfate $\left(\mathrm{CaSO}_{4} \cdot 2 \mathrm{H}_{2} \mathrm{O}\right)$ and calcium carbonate $\left(\mathrm{CaCO}_{3}\right)$, the bands of which fall at 1130, 1050-1015 and $670 \mathrm{~cm}^{-1}$ [50] and 2510-2540, 2230-2130, 1430, 870-880, 715 and $460-430 \mathrm{~cm}^{-1}$ [51], respectively. These substances were used as fillers of the paper to improve its mechanical properties. Ultimately, FTIR spectra shown in Figure 5, taken before and after treatment, do not show appreciable variation, confirming that our treatment does not introduce a valuable modification in the number of significant functional groups (i.e., hydroxyls and carbonyls).

\subsection{PXRD Results}

The untreated paper PXRD pattern is reported in Figure 6. The distinctive diffraction peaks of cellulose are visible at $2 \theta=15.1^{\circ}, 16.8^{\circ}$ and $22.9^{\circ}$ [52]. Several other reflections can be observed in Figure 6 (see insets), proving the presence of other crystalline species.

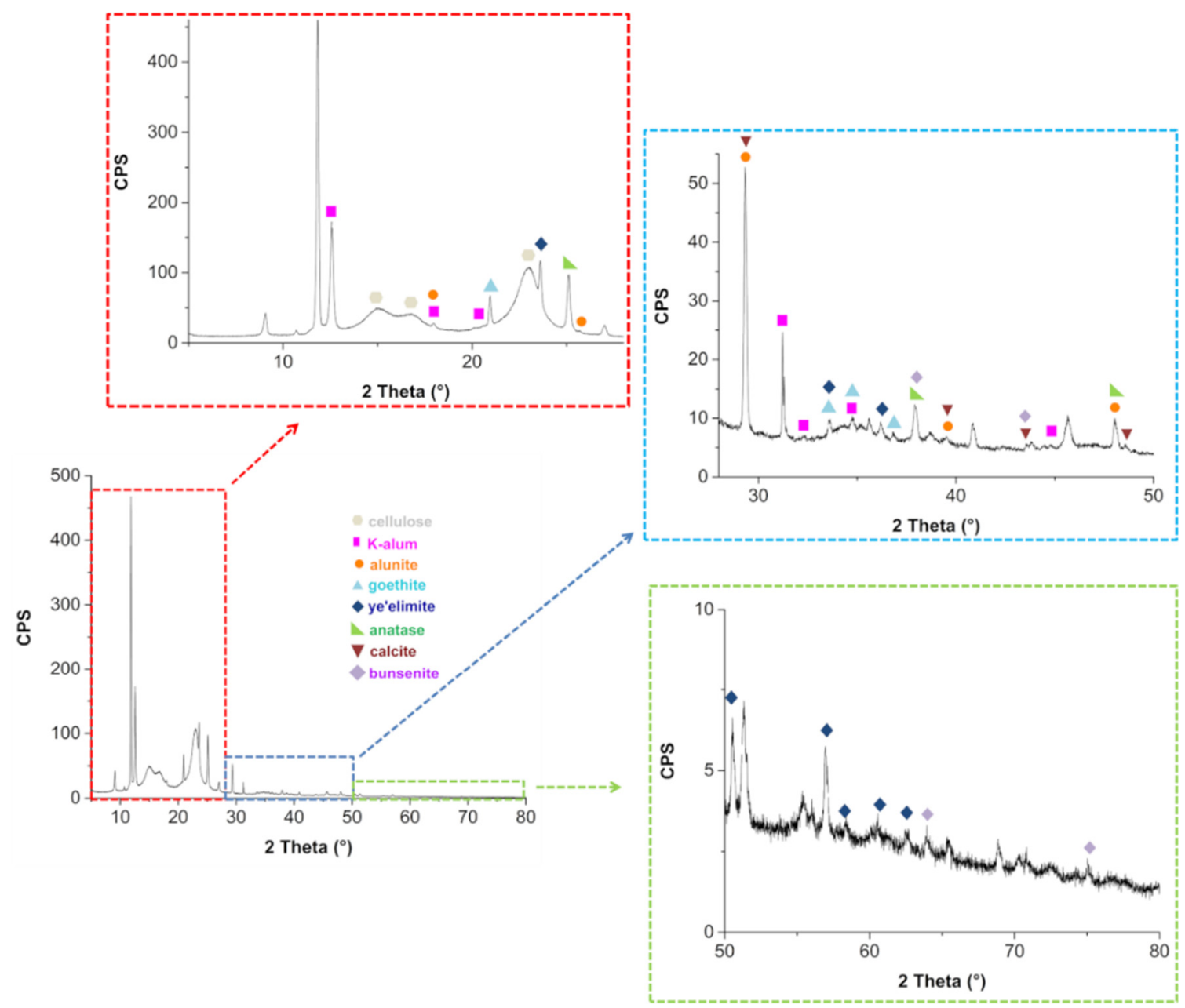

Figure 6. Untreated paper PXRD and related magnifications in the angular ranges $5-28^{\circ}$ (red inset), $28-50^{\circ}$ (blue inset) and $50-80^{\circ}$ (green inset).

These compounds were identified by comparison with reference patterns reported in the Crystallography Open Database (COD) and in the RRUFF database (Table 2). 
Table 2. Crystalline compound identified in PXRD spectra of the book paper (before and after deacidification).

\begin{tabular}{cccc}
\hline PXRD Identified Compound & Common Name & $\mathbf{2 \theta}\left({ }^{\circ}\right)$ & $\mathbf{N}^{\circ} \mathbf{R e f}^{\circ}$ \\
\hline $\mathrm{KAl}\left(\mathrm{SO}_{4}\right)_{2} \cdot 12 \mathrm{H}_{2} \mathrm{O}$ & K-alum & $12.6 ; 17.9 ; 20.4 ; 31.2 ; 32.3 ; 34.7 ; 44.7$ & $\mathrm{R} 040134$ \\
$\mathrm{KAl}\left(\mathrm{SO}_{4}\right)_{2}(\mathrm{OH})_{6}$ & Alunite & $17.9 ; 25.7 ; 29.6 ; 39.4 ; 47.8$ & $\mathrm{R} 060430$ \\
$\mathrm{FeO}(\mathrm{OH})$ & Goethite & $21.0 ; 33.6 ; 34.7 ; 36.8$ & $\mathrm{R} 050142$ \\
$\mathrm{Ca}_{4} \mathrm{Al}_{6} \mathrm{O}_{12}\left(\mathrm{SO}_{4}\right)$ & Ye'elimite & $23.5 ; 33.6 ; 36.3 ; 50.5 ; 56.6 ; 58.4 ; 60.5 ; 62.4$ & $\mathrm{COD} 9009938$ \\
$\mathrm{TiO}_{2}$ & Anatase & $25.1 ; 37.7 ; 47.8$ & $\mathrm{R} 060277$ \\
$\mathrm{CaCO}_{3}$ & Calcite & $29.6 ; 39.4 ; 48.5$ & $\mathrm{R} 040070$ \\
$\mathrm{NiO}$ & Bunsenite & $37.7 ; 43.5 ; 63.5 ; 75.5$ & $\mathrm{R} 080121$ \\
\hline
\end{tabular}

Finally, no differences between the diffractograms obtained after deacidification of the book were observed with respect to those obtained before the treatment. The presence of K-alum and alunite confirms the historical tradition of paper manufacturing of adding $\mathrm{K}$-alum and other similar compounds into the ligno-cellulosic paste, together with animal gelatin $[53,54]$. While FTIR spectra show evidence of the presence of calcium sulfate bihydrate and calcium hydroxide, PXRD spectra do not show evidence of these compounds, at least in the crystalline phase. This is an interesting point that requires a deeper investigation, which is beyond the aim of this work. At the moment, we can only hypothesize that both calcium hydroxide and calcium sulfate may exist in the system as amorphous material dispersed on the cellulose surface. It is worth mentioning that iron appears to be present only as crystalline goethite. It is known [54] that epta-hydrate ferrous sulfate, traditionally defined as green vitriol, was often added to alum to partially substitute this much costly component. Further, ferric alum, a less pure form of alum, obtained by the sulfuric acid treatment of natural bauxite raw materials, could also have been used by paper manufacturing to replace part of alum. Goethite could be derived from bauxite, as this mineral represents one of the major sources of iron in bauxite [55]. Finally, no differences between the diffractograms obtained after deacidification of the book were observed with respect to those obtained before the treatment.

\subsection{X-ray Fluorescence Results}

Six spectra were recorded for each of the analyzed pages. Spectra were all similar to those reported in Figure 7.

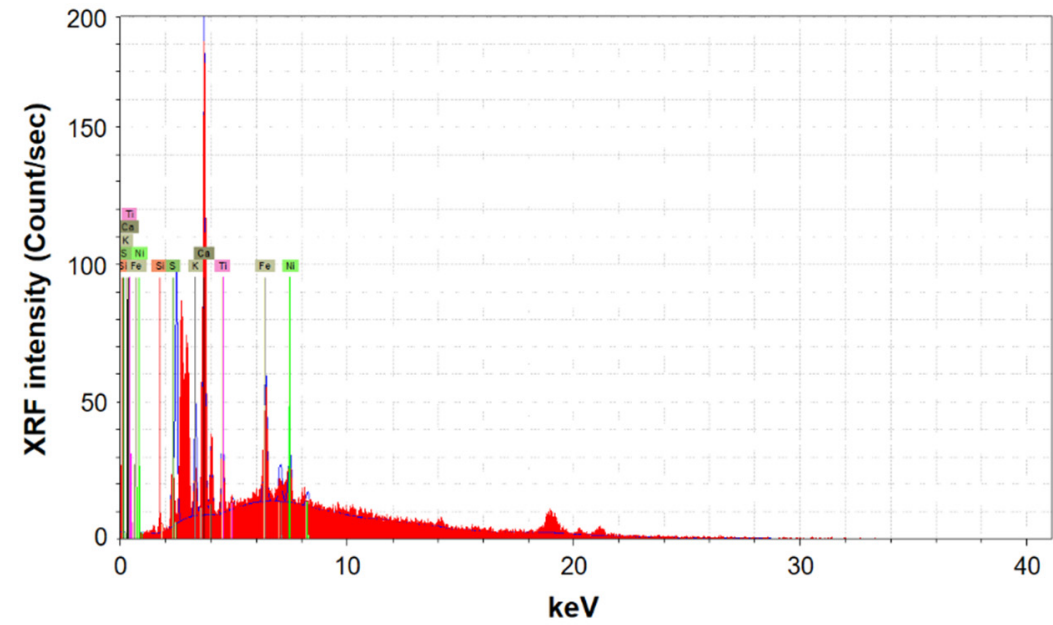

Figure 7. XRF spectra after treatment of Page 1.

The averaged XRF intensity of each of the detected chemical elements, expressed in the scale applied by the instrument (count/s), is summarized in Figure 8. The average was taken on all data recorded from the 12 analyzed pages. The bars represent the standard deviations. 


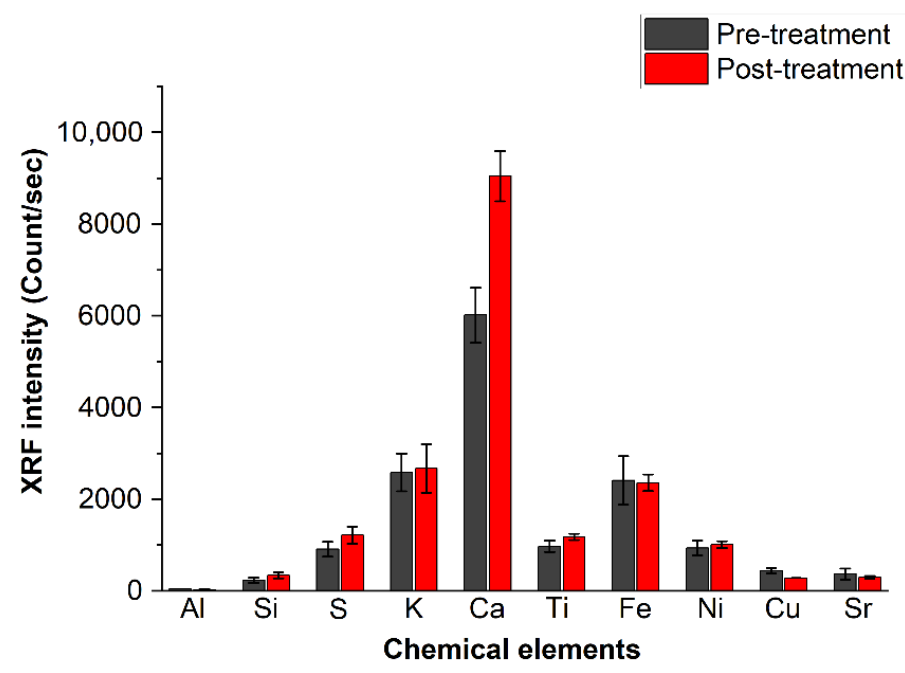

Figure 8. Intensity of the chemical species detected in the paper through XRF before and after deacidifying treatment. The error bars are the standard deviation as obtained from all measurements.

The elements detected through XRF analysis are $\mathrm{Al}, \mathrm{Si}, \mathrm{S}, \mathrm{K}, \mathrm{Ca}, \mathrm{Ti}, \mathrm{Fe}, \mathrm{Ni}, \mathrm{Cu}$ and $\mathrm{Sr}$, from which those found with the highest intensity are calcium, iron, potassium and sulfur, confirming the findings obtained by FTIR and PXRD spectroscopies. The low aluminum intensity in the XRF spectra can be attributed to the low sensitivity of this element in the XRF technique. The XRF signal in Figure 8 shows, as expected from the beginning, that calcium is the only element increased by the deacidification process; the differences before and after treatment are far from the experimental error.

In order to show the uniformity level of calcium deposition in the several analyzed pages, the intensity of the calcium "seen" by the XRF spectra for all pages is reported in Figure 9, where the black line represents the pre-treatment-averaged (on the page) calcium spectral intensity, while the red line shows the trend of the calcium signal after the treatment. An average difference of the order of about $50 \%$ can be observed.

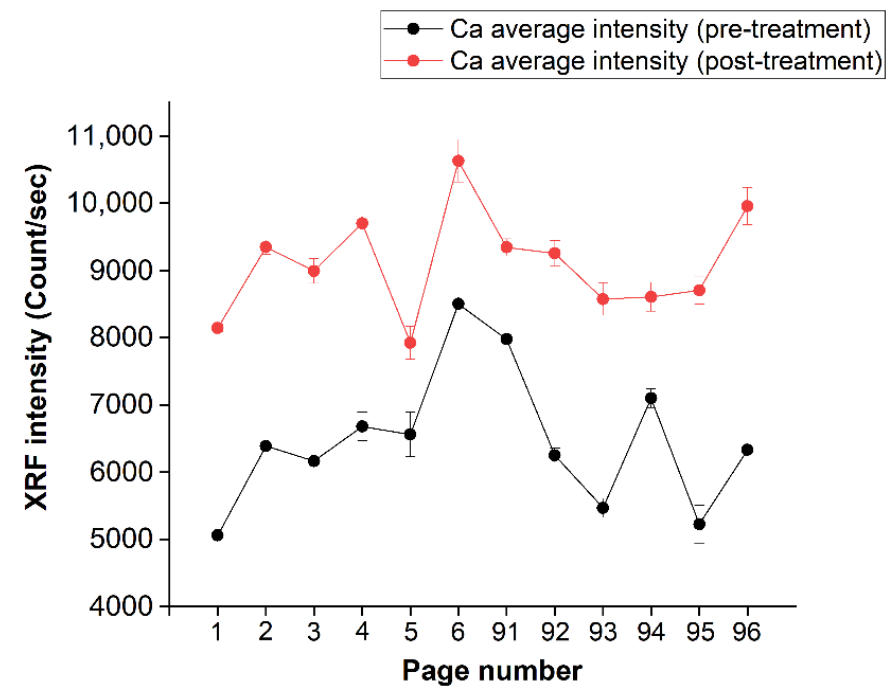

Figure 9. Average of the intensity values, per page, of $\mathrm{Ca}$ (before and after treatment). The pages are shown on the abscissa axis, while the intensity is shown on the ordinate axis.

\section{4. $p H$ Results}

Figure 10 reports the values of averaged $\mathrm{pH}$ values measured on the book pages before treatment and after each nebulization/drying cycle. $\mathrm{pH}$ was also measured even on the book pages kept closed during the deacidification treatment. 


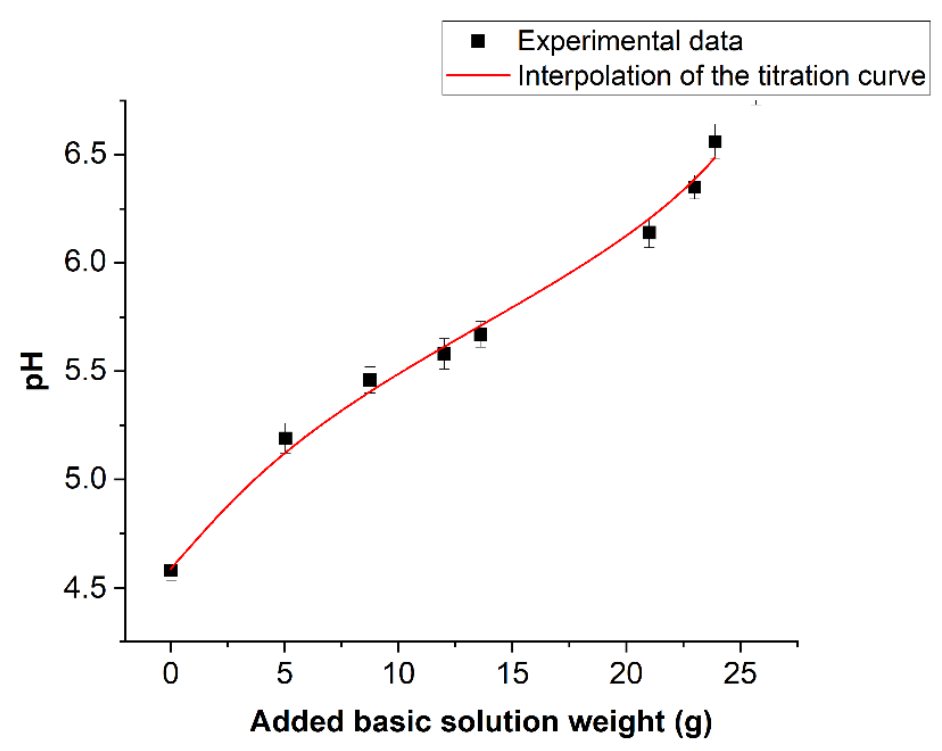

Figure 10. Trend of the average $\mathrm{pH}$ value measured after each complete deacidification treatment.

No $\mathrm{pH}$ variation was observed, confirming that the nebulized solution did not penetrate on these pages. On the abscissa axis, the total amount of basic solution absorbed by the book at the end of every cycle is reported. This quantity was calculated by the following Equation (2):

$$
\mathrm{W}_{\mathrm{J}}=\sum_{\mathrm{i}=1}^{\mathrm{J}} \Delta \mathrm{P}_{\mathrm{i}}
$$

where $\Delta \mathrm{P}_{\mathrm{i}}$ is the variation of the book weight between the $\mathrm{i}$-esimo nebulization stage and the ( $\mathrm{i}-1)$-esimo drying stage. The hypothesis that $\mathrm{W}_{\mathrm{J}}$ is proportional to the average calcium concentration added to the book at the J-esimo nebulization stage will be used in the following. If this increment of the calcium concentration is defined as $b_{\mathrm{J}}$, then the proposed hypothesis can be expressed by the equation $b_{J}=\beta W_{J}$. The trend of the $\mathrm{pH}$ values against $\mathrm{W}_{\mathrm{J}}$ can be considered as a titration curve of the book pages. The continuous line is the interpolation of the titration curve by the simple chemical model illustrated in the following. Taking into consideration the spectroscopic results shown above, it can be hypothesized that the acidity of the book is linked to the hydrolysis of some acid cationic species. To simplify the problem, the dominating effect of a single species was taken into consideration. The identification of this acid species will be discussed next, taking into consideration the acid constant of the involved hydrolysis process coming from the titration curve, as well as the information obtained from spectroscopic and X-ray diffraction data. The starting point is then the general assumption of the presence of a water-soluble compound $C_{n} A_{m}$, where $C$ is hypothesized to be the cation species responsible for the book acidity, while A is its anionic counterpart (A could indeed correspond to more than a single anionic species, but this aspect would not affect at all the model). The presence of humidity leads to the electrolytic dissociation of $C_{n} A_{m}$, according to Equation (3):

$$
\mathrm{C}_{\mathrm{m}} \mathrm{A}_{\mathrm{n}} \rightarrow \mathrm{mC}^{\mathrm{n}+}+\mathrm{nA}^{\mathrm{m}-}
$$

The acidity will then come out as a product of $\mathrm{H}^{+}$due to the hydrolysis of the cation (4):

$$
\mathrm{C}^{\mathrm{n}+}+\mathrm{H}_{2} \mathrm{O} \leftrightarrows \mathrm{C}(\mathrm{OH})^{\mathrm{p}+}+\mathrm{H}^{+}
$$


where, for brevity, the superscript $\mathrm{p}^{+}$was used instead of $(\mathrm{n}-1)^{+}$, and $\mathrm{K}$ is the acidity constant of the hydrolysis process. The hydrolysis equilibrium is represented by Equation (5):

$$
\frac{\left[\mathrm{H}^{+}\right]\left[\mathrm{C}(\mathrm{OH})^{\mathrm{p}+}\right]}{\left[\mathrm{C}^{\mathrm{n}+}\right]}=\mathrm{K}
$$

In order to obtain a useful interpolating equation of the $\mathrm{pH}$ trend reported in Figure 10, $\left[\mathrm{C}(\mathrm{OH})^{\mathrm{p}+}\right]$ and $\left[\mathrm{C}^{\mathrm{n}+}\right]$ need to be expressed in terms of the $\mathrm{C}_{n} \mathrm{~A}_{\mathrm{m}}$ analytic concentration and in terms of the added $\mathrm{Ca}^{2+}$ during the book treatment and $\mathrm{H}^{+}$concentrations. This can be achieved by using the following mass (6) and charge balances (7) at any J stage of treatment.

$$
\begin{gathered}
{\left[\mathrm{C}^{\mathrm{n}+}\right]+\left[\mathrm{C}(\mathrm{OH})^{\mathrm{p}+}\right]=\mathrm{ma}} \\
\frac{\mathrm{n}}{\mathrm{m}}\left(\left[\mathrm{C}^{\mathrm{n}+}\right]+\left[\mathrm{C}(\mathrm{OH})^{\mathrm{p}+}\right]\right)=\left[\mathrm{A}^{\mathrm{m}-}\right]
\end{gathered}
$$

where $\mathrm{a}$ is the $\mathrm{C}_{n} \mathrm{~A}_{\mathrm{m}}$ concentration in the book. The presence of the $\mathrm{OH}^{-}$concentration into Equation (8) leads to a third-order equation in $\mathrm{H}^{+}$, which complicates the finding of an analytic interpolation equation. For this reason, this term has been neglected.

$$
\left[\mathrm{H}_{\mathrm{J}}^{+}\right]+2 \mathrm{~b}_{\mathrm{J}}+\mathrm{n}\left[\mathrm{C}^{\mathrm{n}+}\right]+(\mathrm{n}-1)\left[\mathrm{C}(\mathrm{OH})^{\mathrm{p}+}\right]=\mathrm{m}\left[\mathrm{A}^{\mathrm{m}-}\right]+\left[\mathrm{OH}_{\mathrm{J}}^{-}\right]
$$

The model in this case must be considered strictly valid only when the $\mathrm{OH}^{-}$concentration is two orders of degree lower with respect to the $\mathrm{H}^{+}$concentration and only for the first five points of the graph reported in Figure 10. For the last three points, a greater approximation error of the order of $5 \%$ is introduced. However, such an approximation is of the order of the experimental error. The introduced simplification leads to the following second-order equation in $\mathrm{H}^{+}(9)$.

$$
\left[\mathrm{H}_{\mathrm{J}}^{+}\right]^{2}+\left(2 \mathrm{~b}_{\mathrm{J}}+\mathrm{K}\right)\left[\mathrm{H}_{\mathrm{J}}^{+}\right]+\left(2 \mathrm{~Kb}_{\mathrm{J}}-\mathrm{Kma}\right)=0
$$

Maintaining that $b_{\mathrm{J}}=\beta \mathrm{W}_{\mathrm{J}}$, with being $\mathrm{W}_{\mathrm{J}}$ the amount of basic solution added to the book at the J-esimo nebulization treatment cycle, Equation (10) can be rewritten as Equation (11):

$$
\begin{gathered}
\mathrm{pH}_{\mathrm{J}}=\log 2-\log \left[\sqrt{\left(2 \mathrm{~b}_{\mathrm{J}}-\mathrm{K}\right)^{2}+4 \mathrm{Kma}}-\left(2 \mathrm{~b}_{\mathrm{J}}+\mathrm{K}\right)\right] \\
\mathrm{pH}_{\mathrm{J}}=\log 2-\log \left[\sqrt{\left(2 \beta \mathrm{W}_{\mathrm{J}}-\mathrm{K}\right)^{2}+4 \mathrm{~K} \alpha}-\left(2 \beta \mathrm{W}_{\mathrm{J}}+\mathrm{K}\right)\right]
\end{gathered}
$$

where $\alpha=$ ma. The continuous line in Figure 10 represents the best interpolation of experimental data when $K, \alpha$ and $\beta$ are varied. The fit gave a reduced $\chi$-Square value of 0.993 . Values of optimized parameters were $(1.8 \pm 0.2) \times 10^{-6} \mathrm{~mole} \cdot \mathrm{L}^{-1},(3.86 \pm 0.2) \times 10^{-4} \mathrm{~mole} \cdot \mathrm{L}^{-1}$ and $(0.7 \pm 0.2) \times 10^{-5}$ mole $\cdot L^{-1} \cdot g^{-1}$ for $K, \alpha$ and $\beta$, respectively. Based on these results, and considering the presence of the additive evidenced into the cellulose paste, through the analytic determinations discussed above, a reasonable indication concerning the chemical species responsible for the book acidity can be made. This species should have a hydrolysis $\mathrm{pK}$ around five. On the other hand, the only freely water-soluble additives were evidenced in the paper alum species. On the contrary, the only iron species seen by PXRD is goethite. This compound cannot contribute to book acidity due to its very low solubility. According to Flynn (1984) [56], the solubility $\mathrm{pK}_{\mathrm{sol}}$ of this species is, in fact, 41.7, while the required solubility for the relevant acidifying species must be around $(3.8 \pm 1.3) \times 10^{-4} \mathrm{~mole} \cdot \mathrm{L}^{-1}$ (value of $\alpha$ ). On the other hand, Sarpola (2007) [57] indicates a pK equal to 5.52 for the process reported in Equation (12).

$$
\mathrm{Al}^{3+}+\mathrm{H}_{2} \mathrm{O} \rightarrow \mathrm{Al}(\mathrm{OH})^{2+}+\mathrm{H}^{+}
$$


According to these authors and some of their references [58], the solubility of $\mathrm{Al}^{3+}$ and $\mathrm{Al}(\mathrm{OH})^{2+}$ are of the order of $10^{-4}$, in the $\mathrm{pH}$ range in book pages, and very close to the value predicted by the discussed model. A final comment can be made with respect to the value of the $\beta$ factor giving the proportionality between the amount of basic solution absorbed by the book during the nebulization and the local concentration of calcium in the water droplets added to the paper during the $\mathrm{pH}$ measurement. A theoretical estimation of the $\beta$ factor can be made considering that:

1. A $40 \mu \mathrm{L}$ volume of water droplets is dispersed on the paper to measure the $\mathrm{pH}$, and droplets diffuse on the surface corresponding to the measure electrode surface $\left(0.78 \mathrm{~cm}^{2}\right)$;

2. The total surface of the opened pages, hypothesized to be the only absorbers of the nebulized solution, is equal to $1560 \mathrm{~cm}^{2}$;

3. The concentration of the $\mathrm{Ca}^{2+}$ ion in the nebulized solution is equal to $8.73 \times 10^{-3}$. Simple calculations made on the assumption that the added calcium hydroxide dissolves completely in the water droplet dispersed under the $\mathrm{pH}$ measure electrode would lead to a theoretical value of the $\beta$ factor equal to about $10^{-4}$; that is to say, a value one order of degree bigger with respect to that furnished by the fit of the titration curve. This apparent discrepancy can be explained, in our opinion, considering that a greater part of the added calcium hydroxide can react with the atmospheric $\mathrm{CO}_{2}$, during the drying stage of the paper, becoming calcium carbonate, which remains in the system as an alkaline reserve. On the basis of this hypothesis, the values of $\beta$ could justify a contribution to the alkaline reserve of the order of about $0.15 \%$ of calcium carbonate with respect to the weight of the paper.

\subsection{Colorimetric and Optical Microscopic Analysis Results}

Table 3 reports the values of the chromatic coordinates $\mathrm{L}^{*}, \mathrm{a}^{*}$ and $\mathrm{b}^{*}$, the total color difference $\left(\Delta \mathrm{E}^{*}\right)$ and the whiteness parameter $(\mathrm{W})$ for both the paper and ink in the four different cases: (a) untreated; (b) deacidified; (c) untreated and aged; (d) deacidified and aged.

It can be seen that the paper, before any treatment, shows strong green and yellow components and has a relatively high lightness $\left(L^{*}=70.3 ; a^{*}=-14.2 ; b^{*}=16.3\right)$. The yellow component is explainable in terms of the cellulose oxidation, which turns the white appearance of paper yellow [59]. The only track that could explain the presence of the green component seems linked to the presence of bunsenite $(\mathrm{NiO})$ in the paper, as evidenced by the PXRD analysis. This mineral is known to occur in dark green crystals and could be present as an impurity in the original material used to prepare the alum. It is worth noticing that the deacidifying treatment does not introduce differences in the colorimetric coordinate of both the paper and the ink, which remain the same as the limit of experimental error. The untreated samples lose luminosity $\left(\mathrm{L}^{*}\right)$ (more than 10\%) and whiteness $(\mathrm{W})$ (around $10 \%)$, with a total color difference $\left(\Delta \mathrm{E}^{*}\right)$ of about $11 \%$ with aging treatment. Even worse appear to be the aging effects on the ink, which undergoes an increase in luminosity $(20 \%)$ and whiteness $(30 \%)$, with a total color difference of $24 \%$. It is not easy to explain in detail the reasons for these variations, but they evidence, as expected, a dramatic effect of the aging on the original untreated book. Instead, the colorimetric coordinates of deacidified and aged samples appear to be quite similar to those of the original book. In particular, the whiteness does not change in the limit of measurement error for both the paper and ink, while the total color difference is almost in the range of the experimental error. These colorimetric findings confirm the protective role of the treatment. The stability of ink with respect to the aerosol treatment is also verified by observing the script characters before and after treatment and before and after aging tests by the optical microscope with a magnification of 1000 times. The total absence of bleeding is thus ascertained. 
Table 3. Colorimetric coordinates before and after deacidification treatment and before and after aging.

\begin{tabular}{|c|c|c|c|c|c|}
\hline & Colorimetric & Pages Average & $S^{2}$ & Ink Average & \\
\hline & Coordinate & Value & SD Pages & Value & SD Ink \\
\hline \multirow{4}{*}{ (a) Untreated } & $L^{*}$ & 70.4 & 0.5 & 51.0 & 1.0 \\
\hline & $a^{*}$ & -14.2 & 0.2 & 3.6 & 1.0 \\
\hline & $b^{*}$ & 16.2 & 0.2 & 16.0 & 0.5 \\
\hline & W & 71.8 & 0.7 & 45.3 & 1.2 \\
\hline \multirow{4}{*}{ (b) Deacidified } & $\mathrm{L}^{*}$ & 69.8 & 0.7 & 50.7 & 0.8 \\
\hline & $a^{*}$ & -15.4 & 0.3 & 3.0 & 0.4 \\
\hline & $b^{*}$ & 16.6 & 0.3 & 16.6 & 0.6 \\
\hline & $\mathrm{W}$ & 71.5 & 1.1 & 45.1 & 1.1 \\
\hline \multirow{5}{*}{$\begin{array}{l}\text { Variation between } \mathrm{b} \text { and } \mathrm{a} \\
\text { (deacidified - untreated) }\end{array}$} & $\Delta \mathrm{L}^{*}$ & -0.6 & 1.2 & -0.3 & 1.8 \\
\hline & $\Delta a^{*}$ & -1.2 & 0.6 & -0.6 & 1.4 \\
\hline & $\Delta \mathrm{b}^{*}$ & 0.4 & 0.5 & 0.6 & 1.1 \\
\hline & $\Delta W$ & -0.3 & 1.8 & -0.2 & 2.3 \\
\hline & $\Delta \mathrm{E}^{*}$ & 1.4 & 0.9 & 0.9 & 2.2 \\
\hline \multirow{4}{*}{ (c) Untreated and aged } & $\mathrm{L}^{*}$ & 62.5 & 0.2 & 61.7 & 0.7 \\
\hline & $a^{*}$ & -21.3 & 0.3 & -18.4 & 1.5 \\
\hline & $b^{*}$ & 20.8 & 0.1 & 18.5 & 0.8 \\
\hline & $\mathrm{W}$ & 64.2 & 0.5 & 61.4 & 1.7 \\
\hline \multirow{5}{*}{$\begin{array}{l}\text { Variation between c and a (Untreated } \\
\text { and aged - untreated) }\end{array}$} & $\Delta \mathrm{L}^{*}$ & -7.9 & 0.7 & 9.8 & 1.8 \\
\hline & $\Delta \mathrm{a}^{*}$ & -7.1 & 0.5 & -21.9 & 2.5 \\
\hline & $\Delta \mathrm{b}^{*}$ & 4.5 & 0.2 & 2.5 & 1.4 \\
\hline & $\Delta \mathrm{W}$ & -7.3 & 1.2 & 16.1 & 2.9 \\
\hline & $\Delta \mathrm{E}^{*}$ & 11.5 & 1.0 & 24.1 & 2.6 \\
\hline \multirow{4}{*}{ (d) Deacidified and aged } & $\mathrm{L}^{*}$ & 67.8 & 0.2 & 52.9 & 0.5 \\
\hline & $a^{*}$ & -18.3 & 0.4 & 2.7 & 0.2 \\
\hline & $b^{*}$ & 17.5 & 0.3 & 18.1 & 0.5 \\
\hline & $\mathrm{W}$ & 70.1 & 0.6 & 47.7 & 0.7 \\
\hline \multirow{5}{*}{$\begin{array}{l}\text { Variation between } \mathrm{d} \text { and a } \\
\text { (deacidified and aged - untreated) }\end{array}$} & $\Delta \mathrm{L}^{*}$ & -2.6 & 0.7 & 1.9 & 1.5 \\
\hline & $\Delta \mathrm{a}^{*}$ & -2.9 & 0.7 & -0.9 & 1.2 \\
\hline & $\Delta \mathrm{b}^{*}$ & 1.3 & 0.5 & 2.1 & 1.1 \\
\hline & $\Delta \mathrm{W}$ & -1.7 & 1.2 & 2.4 & 1.9 \\
\hline & $\Delta \mathrm{E}^{*}$ & 4.1 & 1.0 & 2.6 & 2.0 \\
\hline
\end{tabular}

\subsection{Cellulose Degree of Polymerization}

The degree of polymerization of paper, calculated from the limiting specific viscosities, determined as described above, for different samples of paper (untreated, untreated and aged, deacidified, deacidified and aged) are reported in Table 4.

Table 4. Paper's DP before and after deacidification treatment and aging test. The standard deviation on the DP is between 5 and $10 \%$.

\begin{tabular}{cc}
\hline Sample & DP \\
\hline (a) Untreated & $825 \pm 31$ \\
(b) Untreated and aged & $369 \pm 26$ \\
$\Delta \mathrm{DP}=\mathrm{A}-\mathrm{B}$ & $456 \pm 57$ \\
Depolymerization (\%) & 55 \\
(c) Deacidified & $700 \pm 37$ \\
$\Delta \mathrm{DP}=\mathrm{A}-\mathrm{C}$ & $125 \pm 68$ \\
Depolymerization (\%) & 15 \\
(d) Deacidified and aged & $568 \pm 20$ \\
$\Delta \mathrm{DP}=\mathrm{A}-\mathrm{D}$ & $257 \pm 51$ \\
Depolymerization (\%) & 31 \\
\hline
\end{tabular}


Considering that cellulose depolymerization, caused by acid or alkaline hydrolysis and by radical oxidation reactions, appears to be a central mechanism in the aging of paper documents $[1,60]$, the results shown in Table 4 are very encouraging with respect to the goodness of the proposed deacidification mechanism. The aging treatment caused a DP decrease by $55 \%$ on the untreated book, while only a $31 \%$ DP loss was observed for the deacidified sample. Once more, the reduction of acidity appears to be an important cause of book preservation. The treatment generates a decrease of $15 \%$ in DP, probably due to the high $\mathrm{pH}$ of the treatment (more than 12). This does not invalidate the aqueous aerosol technique proposed in this paper, as the treatment $\mathrm{pH}$ can be modified in the future using alkaline water aerosols obtained by diluting the saturated calcium hydroxide solution or using other types of water-soluble alkaline chemicals.

\subsection{Alkaline Reserve Results}

The alkaline reserve introduced by the treatment was determined by following the procedure illustrated in Section 2.9. A $19.35 \mathrm{~mL}$ volume of $\mathrm{NaOH} 0.1 \mathrm{~N}$ was required to neutralize $20 \mathrm{~mL}$ of $\mathrm{HCl} 0.1 \mathrm{~N}$. This corresponds to an alkaline reserve of $0.33 \%$. However, we performed the alkaline reserve test even on the untreated paper.

This was suggested by the PXRD analysis, which evidenced the presence of calcium carbonate on the untreated sample. In the case of untreated paper, the $\mathrm{HCl}$ neutralization required $19.85 \mathrm{~mL}$ of $\mathrm{NaOH}$. This means that a small alkaline reserve $(0.08 \%)$ was already present in the original paper book. Calcium carbonate powder was probably added by the manufacturers of the paper in the past to avoid acidity. Thus, our treatment introduced only about $0.25 \%$ of the alkaline reserve. We did not want to push the treatment above $\mathrm{pH} 6.5$ to avoid alkaline hydrolysis problems. On the other hand, the spectroscopic characterization of the paper shows the contemporaneous presence of calcium carbonate and calcium sulfate. The reason why, after more than one hundred years from paper fabrication, calcium carbonate could survive at around $\mathrm{pH} 4$, is probably due to the passivation of this species by a layer of calcium sulfate on the external surface.

This seems to indicate that the alum rosin was obtained by an alum generated by the reaction of bauxite with sulfuric acid in the presence of carbonate. The presence in the paper of several oxides species such as goethite $(\mathrm{FeO}(\mathrm{OH}))$, bunsenite $(\mathrm{NiO})$ and anatase $\left(\mathrm{TiO}_{2}\right)$ indicates that paper cannot contain free sulfuric acid. This is also confirmed by the pK value of the acid species acting into the book obtained by fitting the titration curve of the paper, which is bigger than five, while the $\mathrm{pK}$ of sulfuric acid is lower than one.

\section{Conclusions}

This paper presents an experiment of book deacidification, where a nebulized water solution of calcium hydroxide was used. A limited amount of this solution was aspersed on the book, followed by the injection of dry air. In this way, deacidification treatment cycles were performed, maintaining the humidity of the book around $0.2 \mathrm{~g}$ of water per page, during the wet phase. The full treatment took about two hours. Only a limited number of pages were kept open during the nebulization treatments to absorb the nebulized solution in order to reduce the time of the experiment, mostly with respect to the different spectroscopic and X-ray diffraction analyses. The book paper additives were characterized by FTIR, PXRD and XRF analyses. This final spectroscopic technique showed that the amount of the added solution during the treatment was almost constant all along the pages of the book kept open. The averaged $\mathrm{pH}$ values plotted versus the amount of the weight of the solution absorbed by the book at each of the treatment cycles was interpreted in terms of a simple model, assuming that the book acidity could be attributed to the hydrolysis of an acid cationic species. Taking into consideration the $\mathrm{pK}$ and the analytic concentration of the cationic species, obtained by the fit of the titration curve and the spectroscopic and $X$-ray diffraction data, the cationic species responsible for the book acidity was identified to be the $\mathrm{Al}^{3+}$ introduced into the paper with the alum additive. Even if the neutralization of the book was performed up to a $\mathrm{pH}$ equal to 6.5 , an alkaline reserve of the order of 
$0.25 \%$ was added to the deacidified book. The treatment appeared to preserve the book during aging, as the depolymerization degree (DP) introduced by aging the deacidified paper was found three times smaller with respect to that of the untreated paper. The colorimetric analysis results confirmed the goodness of the treatment with respect to the preservation of the paper and the ink during aging. We are confident with the fact that the deacidification process reported in this paper can result useful in the future to solve such a big problem, in favor of book conservation, considering that: (a) the full time for the deacidification experiment took about two hours, and the treatment of the full amount of the book pages would only provide a longer treatment time (due to the requirement of a longer nebulization time, estimated of the order of $10 \mathrm{~h}$ ); (b) the treatment can be easily automatized; (c) the humidity introduced into the book during treatment is very limited; (d) the method can be extended, with appropriate apparatus, to a multitude of volumes; (e) the treatment can be generalized by introducing another alkaline medium to the water-based aerosol.

Author Contributions: Conceptualization, G.C. and A.T.; methodology, G.C. and A.T.; software, G.C., A.C., A.T., M.R.B., I.L., G.D.F., C.O.R. and F.S.; validation, G.C., A.C. and A.T.; formal analysis, G.C., A.C., A.T., M.R.B., I.L., G.D.F., C.O.R. and F.S.; investigation, G.C., A.C., A.T., M.R.B., I.L., G.D.F., C.O.R. and F.S.; data curation, G.C., A.C., A.T., M.R.B., I.L., G.D.F., C.O.R. and F.S.; writing-original draft preparation, G.C. and A.T.; writing-review and editing, G.C. and A.T.; supervision, G.C., A.C. and A.T.; project administration, G.C. and A.T. All authors have read and agreed to the published version of the manuscript.

Funding: This research received no external funding.

Institutional Review Board Statement: Not applicable.

Informed Consent Statement: Not applicable.

Data Availability Statement: The datasets generated and analyzed during the current study are available from the corresponding author on reasonable request.

Conflicts of Interest: The authors declare no conflict of interest.

Sample Availability: Samples are not available from the authors.

\section{References}

1. Sequeira, S.; Casanova, C.; Cabrita, E.J. Deacidification of paper using dispersions of $\mathrm{Ca}(\mathrm{OH})_{2}$ nanoparticles in isopropanol. Study of efficiency. J. Cult. Herit. 2006, 7, 264-272. [CrossRef]

2. Hubbe, M.A.; Smith, R.D.; Zou, X.; Katuscak, S.; Potthast, A.; Ahn, K. Deacidification of Acidic Books and Paper by Means of Non-aqueous Dispersions of Alkaline Particles: A Review Focusing on Completeness of the Reaction. BioResources 2017, 12, 4410-4477. [CrossRef]

3. Whitmore, P.M.; Bogaard, J. Determination of the Cellulose Scission Route in the Hydrolytic and Oxidative Degradation of Paper. Restaurator 1994, 15, 26-45. [CrossRef]

4. Cunha, G.M. Mass deacidification for libraries. Libr. Technol. Rep. 1987, 23, 361-472.

5. Smith, R.D. Deacidifying Library Collections: Myths and Realities. Restaurator 1987, 8, 69-93. [CrossRef]

6. Baty, J.W.; Maitland, C.L.; Minter, W.; Hubbe, M.A.; Jordan-Mowery, S.K. Deacidification for the conservation and preserva-tion of paper-based works: A review. BioResources 2010, 5, 1955-2023. [CrossRef]

7. Tursi, A. A Review on Biomass: Importance, Chemistry, Classification, and Conversion. Biofuel Res. J. 2019, 22, 962-979. [CrossRef]

8. Daniels, V.D. The chemistry of paper conservation. Chem. Soc. Rev. 1996, 25, 179-186. [CrossRef]

9. Kačík, F.; Kačíková, D.; Jablonský, M.; Katuščák, S. Cellulose degradation in newsprint paper ageing. Polym. Degrad. Stab. 2009, 94, 1509-1514. [CrossRef]

10. Shahani, C.J.; Harrison, G. Spontaneous Formation of Acids in The Natural Aging of Paper. Stud. Conserv. 2002, 47, 189-192. [CrossRef]

11. Zervos, S. Natural and accelerated ageing of cellulose and paper: A literature review. In Cellulose: Structure and Properties, Derivatives and Industrial Uses; Lejeune, A., Deprez, T., Eds.; Nova Publishing: New York, NY, USA, 2010; pp. $155-203$.

12. Zervos, S.; Moropoulou, A. Cotton Cellulose Ageing in Sealed Vessels. Kinetic Model of Autocatalytic Depolymerization. Cellulose 2005, 12, 485-496. [CrossRef]

13. French, A.D. Glucose, not cellobiose, is the repeating unit of cellulose and why that is important. Cellulose 2017, 24, 4605-4609. [CrossRef] 
14. Romeo, I.; Olivito, F.; Tursi, A.; Algieri, V.; Beneduci, A.; Chidichimo, G.; Maiuolo, L.; Sicilia, E.; De Nino, A. Totally green cellulose conversion into bio-oil and cellulose citrate using molten citric acid in an open system: Synthesis, characterization and computational investigation of reaction mechanisms. RSC Adv. 2020, 10, 34738-34751. [CrossRef]

15. Margutti, S.; Conio, G.; Calvini, P.; Pedemonte, E. Hydrolytic and Oxidative Degradation of Paper. Restaurator 2001, $22,67-83$. [CrossRef]

16. Lienardy, A. Evaluation of Seven Mass Deacidification Treatments. Restaurator 1994, 15, 1-25. [CrossRef]

17. Cedzová, M.; Gállová, I.; Katuščák, S.; Katuščák, M.C.I.G.S. Patents for Paper Deacidification. Restaurator 2006, $27,35-45$. [CrossRef]

18. Stefanis, E.; Panayiotou, C. Protection of Lignocellulosic and Cellulosic Paper by Deacidification with Dispersions of Micro- and Nano-particles of $\mathrm{Ca}(\mathrm{OH})_{2}$ and $\mathrm{Mg}(\mathrm{OH})_{2}$ in Alcohols. Restaurator 2007, 28, 185-200. [CrossRef]

19. Bredereck, K.; Haberditzl, A.; Bluher, A. Paper deacidification in large workshops: Effectiveness and practicability. Restaurator 1990, 11, 165-178. [CrossRef]

20. Brückle, I.; Dambrogio, J. Paper splitting: History and modern technology. J. Am. Inst. Conservat. 2000, 39, 295-325. [CrossRef]

21. Buisson, N. La désacidification de masse rappel historique et technique. L'offre actuelle: Une technique en expansion dans le monde. Actual. Conserv. 2011, 31, 1-15.

22. Lefebvre, A. Une technique encore peu répandue en France: Historique et pratique actuelle de la désacidification à la Biblio-thèque nationale de France. Actual. Conserv. 2012, 31, 1-4.

23. Buchanan, S. An Evaluation of the Bookkeeper Mass Deacidification Process. In Library of Congress; Library of Congress Preservation Directorate: Washington, DC, USA, 1994.

24. Stephens, C.H.; Barrett, T.; Whitmore, P.M.; Wade, J.A.; Mazurek, J.; Schilling, M. Composition and Condition of Naturally Aged Papers. J. Am. Inst. Conserv. 2008, 47, 201-215. [CrossRef]

25. Hubbe, M.; Henniges, U.; Potthast, A.; Ahn, K.; Smith, R. Nonaqueous solution deacidification treatments to prolong the storage life of acidic books: A review of mechanistic and process aspects. BioResources 2018, 13, 7096-7136. [CrossRef]

26. Potthast, A.; Ahn, K. Critical evaluation of approaches toward mass deacidification of paper by dispersed particles. Cellulose 2017, 24, 323-332. [CrossRef]

27. Andres, H.; Blüher, A.; Grossenbacher, G.; Reist, M.; Vogelsanger, B.; Wälchli, M. The Papersave Swiss-Process Quality Control and Efficacy. Restaurator 2008, 29, 3-28. [CrossRef]

28. Giorgi, R.; Dei, L.; Ceccato, M.; Schettino, C.; Baglioni, P. Nanotechnologies for Conservation of Cultural Heritage: Paper and Canvas Deacidification. Langmuir 2002, 18, 8198-8203. [CrossRef]

29. Cheradame, H.; Ipert, S.; Rousset, E. Mass Deacidification of Paper and Books. I: Study of the Limitations of the Gas Phase Processes. Restaurator 2003, 24, 227-239. [CrossRef]

30. Jablonsky, M.; Holubkova, S.; Kazikova, J.; Botkova, M.; Haz, A.; Bajzikova, M. The treatment of acid newsprint paper: Evaluation of treatment by $\mathrm{MgO}$ or by a mixture of $\mathrm{MgO}$ and methyl methoxy magnesium carbonate. Wood Res. 2013, 58, $151-164$.

31. Ramin, M.; Andres, H.; Blüher, A.; Reist, M.; Wälchli, M. Paper de-acidification-A comparative study. J. Pap. Conserv. 2009, 10, $17-25$.

32. Stauderman, S.D.; Brückle, I.; Bischoff, J.J. Observations on the Use of Bookkeeper ${ }^{\circledR}$ Deacidification Spray for the Treatment of Individual Objects; The American Institute for Conservation: Washington, DC, USA, 1996; Volume 15, Available online: http://cool conservation-us.org/coolaic/sg/bpg/annual/v15/bp15--17.html (accessed on 13 July 2016).

33. Reissland, B. Ink Corrosion. Aqueous and Non-Aqueous Treatment of Paper Objects-State of the Art. Restaurator 1999, 20, 167-180. [CrossRef]

34. Smith, A.W. Aqueous deacidification of paper. In Paper and Water: A Guide for Conservators; Banik, G., Bruckle, I., Eds.; Elsevier: Amsterdam, The Netherlands; Butterworth-Heinemann: Oxford, UK, 2011; pp. 341-388.

35. Ambrosi, M.; Dei, L.; Giorgi, R.; Neto, C.; Baglioni, P. Colloidal Particles of $\mathrm{Ca}(\mathrm{OH})_{2}$ : Properties and Applications to Restoration of Frescoes. Langmuir 2001, 17, 4251-4255. [CrossRef]

36. Chen, J.; Fan, H.; Gan, Q.; Gao, D.; Guo, M.; Li, J.; Wang, H. Novel Ancient Book Deacidification Consolidate Reinforcing Device. Patent No. CN207608770U, 13 July 2018.

37. Chen, J.; Fan, H.; Gan, Q.; Gao, D.; Guo, M.; Li, J.; Wang, H. New Type of Ancient-Book Deacidification and Reinforcing and Strengthening Apparatus. Patent No. WO2019105489A1, 6 June 2019.

38. Fan, H.; Guo, M.; Li, J.; Liu, J.; Liu, Q.; Xie, K. A Deacidification Strengthening Device for Whole Sets of Ancient Books in Batch. Patent No. CN108914701, 30 November 2018.

39. Fan, H.; Guo, M.; Li, J.; Liu, J.; Liu, Q.; Xie, K. Deacidification Reinforcing Device Capable of Being Used for Whole Ancient Books in Batches. Patent No. CN208857593U, 14 May 2019.

40. Chen, J.; Fan, H.; Gan, Q.; Gao, D.; Guo, M.; Li, J.; Wang, H. Novel Method for Repairing Ancient Book by Deacidification. Patent No. WO2019105168A1, 6 June 2019.

41. Kratzert, A.; Leisch, N.; Zitzmann, P. Process and Apparatus for Deacidifying Books. Patent No. EP1283300A2, 12 December 2003.

42. TAPPI. Surface pH Measurement of Paper, TAPPI T529 om-99; 2002-2003 TAPPI Test Method; TAPPI Press: Atlanta, GA, USA, 2002.

43. Bégin, P.L.; Kaminska, E. Thermal Accelerated Ageing Test Method Development. Restaurator 2002, 23, 89-105. [CrossRef]

44. Brainard, D.H. Color Appearance and Color Difference Specification. In The Science of Color; Shevell, S., Ed.; Elsevier Science: London, UK, 2003; pp. 191-216. 
45. Gooch, J.W. Whiteness Index. In Encyclopedic Dictionary of Polymers; Gooch, J.W., Ed.; Springer: New York, NY, USA, 2011 ; p. 811.

46. UNI. UNI 8282 Cellulose in Dilute Solutions-Determination of Limiting Viscosity Number-Method in Cupri-Ethylene-Diamine (CED) Solution-Equivalent to the ISO Standard 5351/1; Italian National Unification Body (UNI): Milano, Italy, 1994.

47. TAPPI. Alkalinity of Papers Calcium Carbonate (Alkaline Reserve of Paper), TAPPI T533 pm-92; 2002-2003 TAPPI Test Method; TAPPI Press: Atlanta, GA, USA, 2002.

48. Garside, P.; Wyeth, P. Identification of Cellulosic Fibres by FTIR Spectroscopy-Thread and Single Fibre Analysis by Attenuated Total Reflectance. Stud. Conserv. 2003, 48, 269-275. [CrossRef]

49. Librando, V.; Minniti, Z.; Lorusso, S. Ancient and Modern Paper Characterization by FTIR and Micro-Raman Spectroscopy. Conserv. Sci. Cult. Herit. 2011, 11, 249-268.

50. Hospodarova, V.; Singovszka, E.; Stevulova, N. Characterization of Cellulosic Fibers by FTIR Spectroscopy for Their Further Implementation to Building Materials. Am. J. Anal. Chem. 2018, 9, 303-310. [CrossRef]

51. Miller, F.A.; Wilkins, C.H. Infrared Spectra and Characteristic Frequencies of Inorganic Ions. Anal. Chem. 1952, $24,1253-1294$. [CrossRef]

52. French, A.D. Idealized powder diffraction patterns for cellulose polymorphs. Cellulose 2013, 21, 885-896. [CrossRef]

53. Strazdins, E. Theoretical and practical aspects of alum use in papermaking. Nord. Pulp Pap. Res. J. 1989, 4, 128-134. [CrossRef]

54. Hubbe, M.A.; Bowden, C. Handmade paper: A review of its history, craft, and science. BioResources 2009, 4, 1736-1792. [CrossRef]

55. Liu, Y.; Naidu, R. Hidden values in bauxite residue (red mud): Recovery of metals. Waste Manag. 2014, 34, 2662-2673. [CrossRef] [PubMed]

56. Flynn, C.M. Hydrolysis of inorganic iron(III) salts. Chem. Rev. 1984, 84, 31-41. [CrossRef]

57. Sarpola, A. The Hydrolysis of Aluminium, a Mass Spectrometric Study. Ph.D. Thesis, University of Oulu, Oulu, Finland, 2007.

58. Snoeyink, V.L.; Jenkins, D. Water Chemistry; Wiley and Sons: New York, NY, USA, 1980.

59. Conte, A.M.; Pulci, O.; Knapik, A.; Bagniuk, J.; Del Sole, R.; Lojewska, J.; Missori, M. Role of cellulose oxidation in the yellowing of ancient paper. Phys. Rev. Lett. 2012, 108, 158301. [CrossRef] [PubMed]

60. Ahn, K.; Henniges, U.; Blüher, A.; Banik, G.; Potthast, A. Sustainability of Mass Deacidification. Part I: Concept, Selection of Sample Books and pH-Determination. Restaurator 2011, 32, 48-75. [CrossRef] 